Sang-Yeop Chung, Pawel Sikora, Dong Joo Kim, Mohamed E. El Madawy, Mohamed Abd Elrahman

\title{
Effect of different expanded aggregates on durability-related characteristics of lightweight aggregate concrete
}

Journal article | Accepted manuscript (Postprint)

This version is available at https://doi.org/10.14279/depositonce-11384

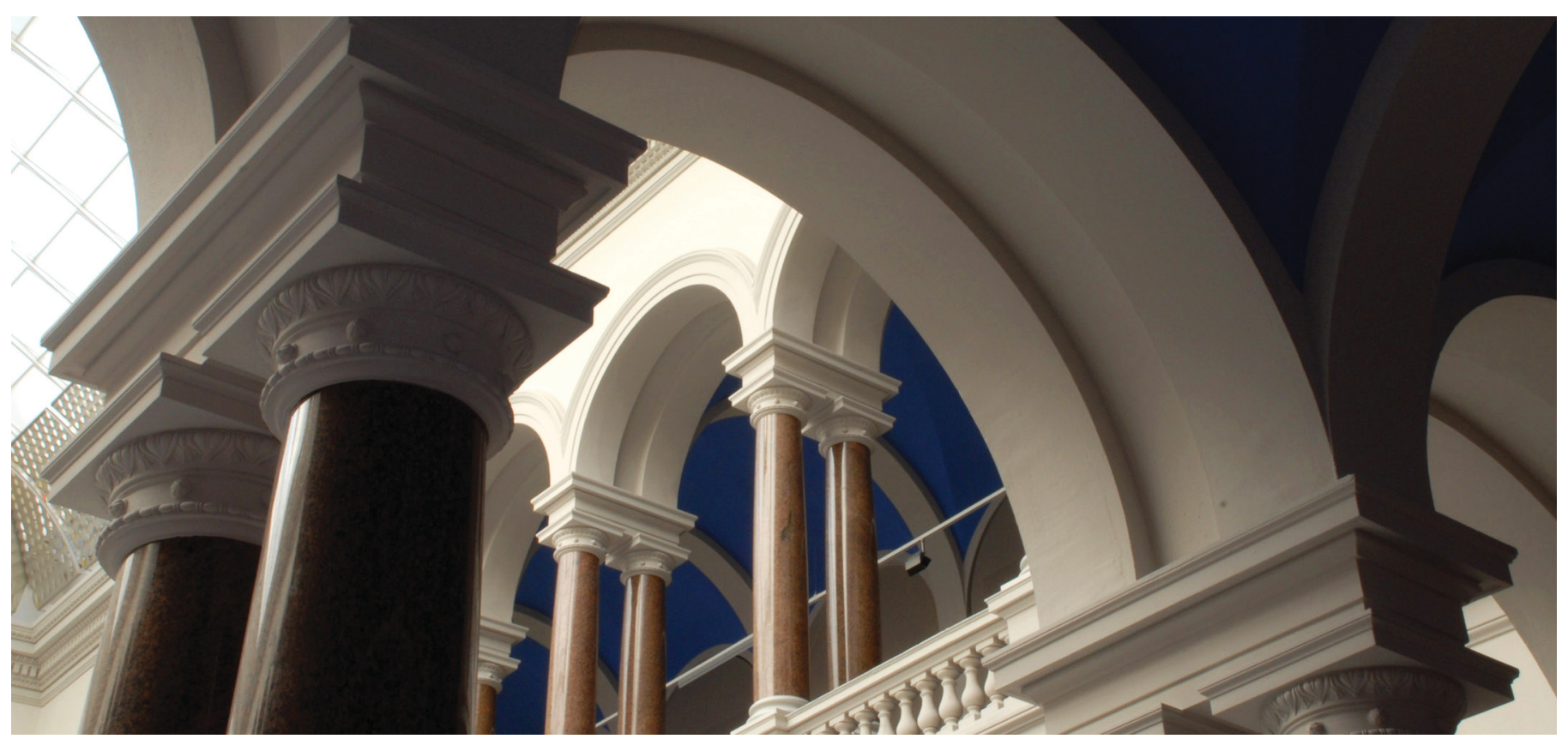

Chung, S.-Y., Sikora, P., Kim, D. J., El Madawy, M. E., \& Abd Elrahman, M. (2021). Effect of different expanded aggregates on durability-related characteristics of lightweight aggregate concrete. Materials Characterization, 173, 110907. https://doi.org/10.1016/j.matchar.2021.110907 
Accepted manuscript of: Chung, S.-Y, Sikora, P., Kim, D. J., El Madawy, M.E., Abd Elrahman, M. (2021). Effect of different expanded aggregates on durability-related characteristics of lightweight aggregate concrete. Materials Characterization, 173, 110907.

https://doi.org/10.1016/j.matchar.2021.110907

This manuscript version is made available under the CC-BY-NC-ND 4.0 license

http://creativecommons.org/licenses/by-nc-nd/4.0/

\title{
Effect of different expanded aggregates on durability-related characteristics of lightweight aggregate concrete
}

\author{
Sang-Yeop Chung ${ }^{\mathrm{a}}$, Pawel Sikora ${ }^{\mathrm{b}, \mathrm{c}}$, Dong Joo Kim ${ }^{\mathrm{a}}$, Mohamed E. El Madawy ${ }^{\mathrm{d}}$, Mohamed Abd Elrahman ${ }^{\mathrm{d}, *}$ \\ ${ }^{a}$ Department of Civil and Environmental Engineering, Sejong University, Seoul 05006, Republic of Korea \\ ${ }^{b}$ Department of Civil Engineering, Technische Universität Berlin, Berlin 13355, Germany \\ ${ }^{c}$ Faculty of Civil and Environmental Engineering, West Pomeranian University of Technology Szczecin, 70-311 Szczecin, Poland \\ ${ }^{d}$ Structural Engineering Department, Mansoura University, Mansoura City 35516, Egypt
}

\begin{abstract}
Lightweight aggregate concrete (LWAC) has relatively larger porosity than conventional concrete, mainly due to the incorporation of porous lightweight aggregates. The types of used lightweight aggregates are critical in determining the physical properties of LWAC, and it is therefore important to examine their effects on the durable characteristics of the material. To perform comparative analysis, the concrete mixture designs with two theoretical density classes were developed. The mixture composition for each class was constant and the only variable parameter was the type of the used lightweight aggregates-expanded glass (Liaver $\left.{ }^{\circledR}\right)$, expanded clay (Liapor ${ }^{\circledR}$ ), and foam glass $\left(\right.$ Ecoglas $\left.{ }^{\circledR}\right)$. Accordingly, their pore characteristics and durability-related properties, such as sorptivity, open water porosity, and water penetration depth, were examined. To understand these phenomena, the permeable characteristic, tortuosity, was also calculated using a numerical approach incorporating X-ray micro-computed tomography. The examined results confirm that the durability characteristics of LWAC are strongly affected by the used aggregate types and are highly correlated with their pore structures. In terms of permeable characteristics, expanded glass is the most beneficial material among the used particles, and the systematic approach in this study can be used to examine the durability characteristic of LWAC.
\end{abstract}

Keywords: lightweight concrete, lightweight aggregates, durability, micro-CT, characterization, microstructure 


\section{Introduction}

Lightweight concrete, which has a relatively lower density than conventional (normal-weight) concrete not exceeding $2000 \mathrm{~kg} / \mathrm{m}^{3}$, is a type of concrete that includes numerous pores or lightweight components, which reduce its dead weight $[1,2]$. Due to advantages, such as low density, advanced insulation, and noise reduction performance, lightweight concrete is widely used in the construction industry [3, 4]. It can be classified into two categories: foamed concrete and lightweight aggregate concrete. The former is composed of binder and pores produced by the use of a foaming agent in general $[5,6]$, while the latter consists of a binder and lightweight aggregates [7, 8]. As a structural component, lightweight aggregate concrete can be considered more beneficial than foamed concrete because of its mechanical properties $[9,10]$.

Lightweight aggregate concrete (LWAC) is a versatile lightweight material that satisfies both thermal and mechanical performance requirements, i.e. relatively low thermal conductivity and appropriate compressive strength, considering its material density $[11,12]$. Highly porous natural or synthetic lightweight aggregates are used to produce LWAC; it is their presence which is the main reason for the low bulk density [13]. More than $50 \%$ of the concrete volume in LWAC is occupied by lightweight aggregates, with their properties and characteristics being critical parameters in determining LWAC performance $[14,15]$. For instance, the physical and mineralogical properties of aggregates can affect the thermal conductivity and compressive strength of lightweight concrete by up to $25 \%$ at the same density level $[16,17,18,19]$. Several types of lightweight aggregates are available for use in the production of the LWAC. These can enhance a large variety of properties such as density, mechanical properties, thermal conductivity, and durability [20]. According to EN 13055 [21], lightweight aggregates are granular materials of mineral origins having a particle density not exceeding $2000 \mathrm{~kg} / \mathrm{m}^{3}$. Lightweight aggregates can be classified into the natural kind, manufactured from natural sources, and those manufactured using the by-products or recycled materials [22]. Various lightweight aggregates of different origins were used in LWAC, such as recycled masonry rubbles [23], lowsilicon iron tailings [24], municipal solid waste incinerator (MSWI) fly ash [25], water treated sludge [26], expanded polystyrene (EPS) [27], raw rice husk [28], and crushed glass [29]. Lightweight aggregates from natural resources can be also used for production of lightweight concrete, such as expanded perlite [30], vermiculite [31], and natural pumice [32]. Expanded artificial lightweight materials from different sources, such as expanded glass (Liaver ${ }^{\circledR}$ and Poraver ${ }^{\circledR}$ ) and expanded clay $\left(\right.$ Liapor $^{\circledR}$ and Leca $\left.{ }^{\circledR}\right)$, were also utilized in lightweight aggregate concrete. These lightweight aggregates have been widely used in the construction and building industries, due to their superior performance in insulation and the reduction of dead weight $[33,34]$.

\footnotetext{
${ }^{*}$ Corresponding author

Email address: mohamedattia@mans.edu.eg (Mohamed Abd Elrahman)
} 
The use of LWAC aims at producing low-density materials with minimal strength loss, with the characteristics of the used lightweight aggregates being important in controlling material properties [35, 36]. The low particle density of lightweight aggregates is created by entrapped air forming an internal cellular pore system. In this procedure, lightweight aggregates tend to lose some mechanical performance, but insulation and noise reduction characteristics are enhanced with increased porosity. As with other types of concrete, both mechanical and physical properties-such as compressive strength and thermal conductivity-are the most important criteria in evaluating the performance of lightweight aggregate concrete [8, 10,37]. Conventional concrete is a durable material which has high resistance to severe changes upon decades of long exposure to the external environment [38]. Since concrete is potentially vulnerable to certain circumstances, its durability-related properties, such as water absorption or permeability, need to be taken into consideration as important variables [39, 40]. The durability of lightweight concrete depends mainly on its major components: i.e. binder and lightweight aggregates. When using lightweight aggregates, the connectivity of the pore system is particularly important in governing durability in comparison to conventional concrete using the same cement paste. The water absorption of lightweight aggregates is an influential parameter in the design and production of lightweight concrete [22]. Compared with normal-weight aggregates, the water absorption of lightweight aggregates significantly affects the workability of LWAC as well as its hardened properties [41]. Lightweight aggregates have a negative effect on concrete workability, especially in the case of transport concrete, which should be workable for an extended period. In addition, lightweight particles can hold more moisture than normal aggregates; this can affect the physical properties of concrete significantly, depending on the pore system and its connectivity [34].

As mentioned above, LWAC generally has a porous structure, particularly in materials with low density, with its permeability also being an important parameter in material durability [42, 43]. It is well known that the high permeability of concrete contributes to accelerate the access for both water and other substances, which damages the concrete itself or the steel embedded in it $[44,45]$. Several studies investigated the permeability of cement-based materials. The permeable pores of LWAC with silica sludge, fly ash, or paper mud was measured by means of mercury intrusion porosimetry (MIP) [46], and the effect of pre-wetted aggregates on LWAC was also evaluated [47]. The permeable characteristics of cold bonded fly ash lightweight aggregate [48], expanded polystyrene aggregates [49], and lapilli lightweight aggregates [50] were also investigated. Nondestructive investigations using X-ray micro-computed tomography were performed to examine pore structures and permeability in concrete [51, 52]. Although its significance, the permeable or durability-related characteristics of LWAC have rarely been performed than other properties, such as compressive strength and thermal conductivity. In particular, nondestructive and microstructural investigation, which can contribute to the material development, have rarely been conducted.

This study mainly aims to investigate the effects of different lightweight aggregates on durability-related properties 
using several approaches. Three expanded lightweight aggregates from different origins were used: expanded clay (Liapor $\left.{ }^{\circledR}\right)$, expanded glass $\left(\right.$ Liaver $\left.^{\circledR}\right)$, and foamed glass $\left(E \operatorname{coglas}{ }^{\circledR}\right)$. The used lightweight aggregates were made of recycled materials which can be considered environmental friendly, with densities lower than that of their source materials. A set of LWAC specimens with different density levels were produced with these lightweight aggregates. In each density class, only the type of aggregates was considered as a variable in order to clarify the effect of aggregate on the LWAC characteristics. Properties of concrete, such as compressive strength and thermal conductivity, were investigated in the previous study [53], with this work concerned only properties related to durability characteristics. To examine the inner structures of the specimens without destruction, X-ray micro-computed tomography (micro-CT) was adopted, with different pore characteristics investigated using the obtained images. Micro-CT was employed to investigate the pore structure of the cement matrix as well as that of lightweight aggregate and correlate them with the durability characteristics of concrete. Permeable characteristics were evaluated via tortuosity, which is a parameter describing the curvature of a pore network $[54,55]$. A discussion of the correlation between overall material properties and pore characteristics can be found then, together with a demonstration of the effectiveness of each expanded lightweight aggregate on the durability characteristics of concrete.

\section{Materials and mixture design properties}

This study examined the influence of three different types of lightweight aggregate on the porosity, permeability and sorptivity of lightweight concrete. Two theoretical classes of oven-dry density were considered for the specimens with expanded glass aggregates (Liaver ${ }^{\circledR}$ ): 600 and $800 \mathrm{~kg} / \mathrm{m}^{3}$. To compare the effect of different aggregates on LWAC, the aggregate volume, cement content, and w/b ratio for each density series were fixed, and only the aggregate type was replaced in the specimens with the same density level. The detailed description of the specimens will be discussed in the following sections. For all mixes, blast furnace slag cement CEM III A $42.5 \mathrm{~N}-$ in accordance with EN 197-1-was used. Microsilica slurry (Silicol) provided by Sika (Germany) and complying with EN 12363-1 was used to improve both the stability and cohesion of the fresh mixtures and to enhance the properties of the hardened concrete. The chemical compositions and particle size distributions of the cement and microsilica are presented in Table 1 and Fig. 1, respectively. The quality of lightweight concrete with a low density $\left(<1000 \mathrm{~kg} / \mathrm{m}^{3}\right)$ is very sensitive to the volume of its ingredients. In its fresh state, LWAC can suffer from segregation and bleeding. To overcome this problem, an admixture that can enhance viscosity (Stabilizer-ST 10160317, Sika Germany) was used, which can improve the cohesion between the components of the mixture and prevent the separation of individual particles. For LWAC with such a low density, compaction and vibration are not recommended due to the difference between the density of lightweight aggregate and the cement paste. Therefore, the produced concrete needs to have 
high consistency class so that it can be cast without external energy. This can be achieved by adding water-reducing admixture (PCE superplasticizer), which is compatible with both cement and viscosity-enhancing admixtures. In this study, superplasticizer (Viscocrete 2014) provided by Sika Germany was used to obtain the target consistency class of F4/F5, as specified in EN 206-1.

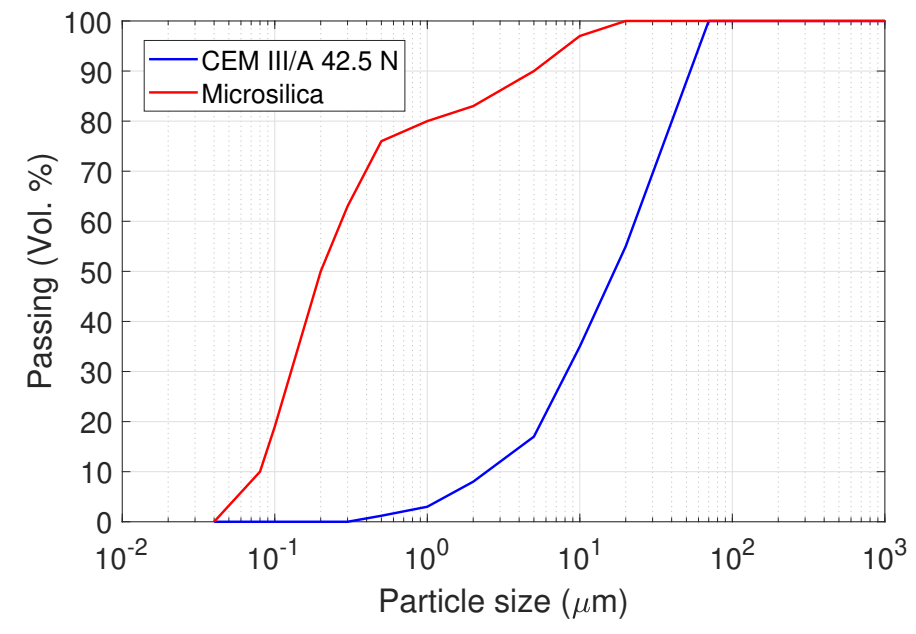

Figure 1: Particle size distributions of the fine materials

Table 1: Physical and chemical properties of cement and microsilica [wt.\%]

\begin{tabular}{cccccccccccc}
\hline Material & $\mathbf{C a O}$ & $\mathbf{S i O}_{2}$ & $\mathrm{Al}_{2} \mathbf{O}_{3}$ & $\mathbf{F e}_{2} \mathbf{O}_{3}$ & $\mathbf{M g O}$ & $\mathbf{N a}_{2} \mathbf{O}$ & $\mathbf{K}_{2} \mathbf{O}$ & $\mathbf{S O}_{3}$ & $\begin{array}{c}\text { Specific } \\
\text { density }\end{array}$ & $\begin{array}{c}\text { Loss on } \\
\text { ignition } \\
(\mathbf{L o I})\end{array}$ & $\begin{array}{c}\text { Surface } \\
\mathbf{a r e a} \\
{\left[\mathbf{m}^{2} / \mathbf{k g}\right]}\end{array}$ \\
\hline $\begin{array}{c}\text { CEM III/A 42.5 N } \\
\text { Microsilica }\end{array}$ & 54.79 & 23.72 & 8.81 & 1.46 & 5.22 & 0.31 & 0.58 & 2.41 & 2.7 & 3.06 & 386.5 \\
& 0.21 & 98.42 & 0.21 & 0.01 & 0.1 & 0.11 & 0.19 & 0.09 & 0.66 & 2.21 & 20000 \\
\hline
\end{tabular}

\subsection{Types of different lightweight aggregates}

Three different types of lightweight aggregates with different densities, strength, and water absorption were used. The mechanical and durability characteristics of LWAC are strongly affected by aggregates properties, with their size, shape, distribution, and pore connectivity. The following lightweight aggregates with different characteristics were taken into consideration and tested in this study:

- Liapor ${ }^{\circledR}$ (expanded clay): Liapor ${ }^{\circledR}$ is made of high-quality clay, burnt in a rotary kiln at a temperature of about $1200{ }^{\circ} \mathrm{C}$. The process creates lightweight aggregates with very fine pores, complying with EN 13055, as can be seen in Fig. 2(a). The material is available on the market from a $2 \mathrm{~mm}$ size, with smaller fractions available only in crushed form, which results in substantially higher density and water absorption than rounded fractions. 

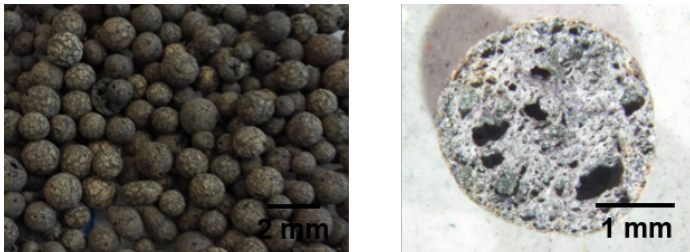

Expanded clay (Liapor ${ }^{\circledR}$ )

(a)
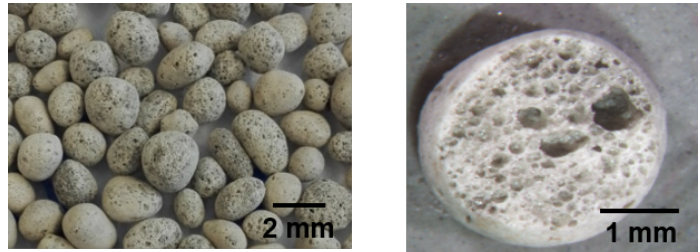

Expanded glass (Liaver ${ }^{\circledR}$ )

(b)
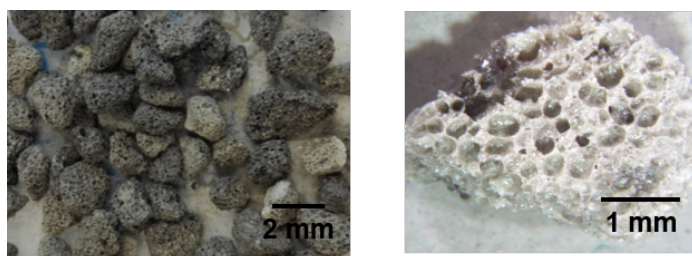

Foamed glass (Ecoglas ${ }^{\circledR}$ )

(c)

Figure 2: The used expanded lightweight aggregates: (a) Liapor ${ }^{\circledR}$, (b) Liaver ${ }^{\circledR}$, (c) Ecoglas ${ }^{\circledR}$ (Note: in each case, the images on the left are the aggregates, while those on the the right are light microscopy images.)

- Liaver ${ }^{\circledR}$ (expanded glass): Liaver ${ }^{\circledR}$ is a type of expanded glass made from recycled glass by sintering the source material in a rotary kiln at a temperature of up to $900{ }^{\circ} \mathrm{C}$. Expanded glass particles are spherical with smooth surfaces and encapsulated air pores within a shell. They comply with EN 13055, as shown in Fig. 2(b). Compared to expanded clay, expanded glass has a lower density, less water absorption, and lower crushing strength.

- Ecoglas ${ }^{\circledR}$ (foamed glass): Ecoglas ${ }^{\circledR}$ is made of recycled glass by grinding the glass to a fine powder and mixing it with a foaming agent. The mixture was heated to $1000{ }^{\circ} \mathrm{C}$ until a foaming process took place. The produced particles are cellular materials with low density, as can be seen in Fig. 2(c).

The physical and mechanical properties of the used lightweight aggregates were measured experimentally as presented in Table 2. Their water absorptions were also measured at $60 \mathrm{~min}$ and at $24 \mathrm{~h}$ in accordance with EN 1097-6.

\subsection{Mix composition and mixing procedure}

In this study, two different series of concrete mixes were designed and prepared to investigate the influence of lightweight aggregate types as well as their densities on the properties of LWAC. For this purpose, two different densities, 600 and $800 \mathrm{~kg} / \mathrm{m}^{3}$, were considered. In order to compare the performance of lightweight aggregates with different densities, the design process of LWAC mixtures has to be undertaken carefully. In general, one of two common approaches can be used to design such mixtures: with a constant oven-dry density for each series 
Table 2: Mechanical and physical properties of the used lightweight aggregates

\begin{tabular}{|c|c|c|c|c|c|}
\hline Material & Shape & $\begin{array}{c}\text { Particle density } \\
{\left[\mathrm{kg} / \mathrm{m}^{3}\right]}\end{array}$ & $\begin{array}{c}\text { Crushing resistance }^{*} \\
{\left[\mathrm{~N} / \mathbf{m m}^{2}\right]}\end{array}$ & $\begin{array}{l}\text { Water absorption } \\
60 \text { min [wt. } \% \text { ] }\end{array}$ & $\begin{array}{c}\text { Water absorption } \\
24 \mathrm{~h}[\mathrm{wt} . \%]\end{array}$ \\
\hline Liapor $^{\circledR} 2-8 \mathrm{~mm}$ & Rounded & 540 & $\geq 0.9$ & 13.0 & 18.0 \\
\hline Liapor ${ }^{\circledR}$ 2-6 mm & Rounded & 670 & $\geq 1.6$ & 13.0 & 16.0 \\
\hline Liapor ${ }^{\circledR}$ 1-4 mm & Rounded & 850 & $\geq 2.2$ & 11.0 & 13.0 \\
\hline Liapor $^{\circledR}$ 0-2 mm & Crushed & 1350 & $\geq 4.0$ & 23.6 & 30.0 \\
\hline Liaver $^{\circledR} 4-8 \mathrm{~mm}$ & Rounded & 300 & $\geq 1.9$ & 7.3 & 13.6 \\
\hline Liaver $^{\circledR} 2-4$ mm & Rounded & 310 & $\geq 2.2$ & 8.9 & 14.4 \\
\hline Liaver $^{\circledR}$ 1-2 mm & Rounded & 350 & $\geq 2.4$ & 10.3 & 15.8 \\
\hline Liaver $^{\circledR} 0.5-1 \mathrm{~mm}$ & Rounded & 450 & $\geq 2.9$ & 9.0 & 15.4 \\
\hline $\operatorname{Ecoglas}^{\circledR} 5-8 \mathrm{~mm}$ & Crushed & 310 & $\geq 1.0$ & 15.6 & 27.3 \\
\hline $\operatorname{Ecoglas}^{\circledR} 2-5 \mathrm{~mm}$ & Crushed & 340 & $\geq 2.4$ & 13.8 & 25.5 \\
\hline $\operatorname{Ecoglas}^{\circledR} 0-2 \mathrm{~mm}$ & Crushed & 1050 & $\geq 3.0$ & 11.7 & 21.6 \\
\hline
\end{tabular}

* data provided by manufacturers

(where the aggregate volume is different) or with a constant aggregate volume for each series (with a different dry density according to the aggregate density). In the former approach, the lightweight aggregate volume can be varied, which can cause a change in concrete properties related to other factors, not by aggregate type. The latter approach was therefore selected here, where the aggregate volume, cement content, and w/b ratio were fixed in each density class, as shown in Table 3. Here, the specimens with Liapor $^{\circledR}$, Liaver $^{\circledR}$, and Ecoglas ${ }^{\circledR}$ were denoted as LP, LV, and EG, respectively. The size distributions of the used aggregate particles in each specimen are also presented in Fig. 3. In each case, the number 1 is for the specimen with lower density, and the number 2 is for the higher density specimen. The lightweight concrete mixture with expanded glass (Liaver ${ }^{\circledR}$ ) was considered as the reference mix, with the mix compositions designed to achieve the target dry density levels of 600 and $800 \mathrm{~kg} / \mathrm{m}^{3}$. In the mixtures with the other lightweight aggregates, the same volume of expanded glass was replaced with the other materials: expanded clay $\left(\right.$ Liapor $\left.{ }^{\circledR}\right)$ and foamed glass (Ecoglas ${ }^{\circledR}$ ). For each type of lightweight aggregate, two mixtures with different densities were prepared and tested; this approach allows to evaluate solely the effect of the aggregate type itself on the durability-related properties of concrete. In the reference specimens with expanded glass, the water-binder (w/b) ratios were fixed at $0.77\left(600 \mathrm{~kg} / \mathrm{m}^{3}\right)$ and $0.43\left(800 \mathrm{~kg} / \mathrm{m}^{3}\right)$. Regarding mixture proportions, the dense packing concept was adopted to calculate the required volume of lightweight aggregates: i.e. $68.3 \%$ and $57.7 \%$ for the $600 \mathrm{~kg} / \mathrm{m}^{3}$ and $800 \mathrm{~kg} / \mathrm{m}^{3}$ in the LV specimens (reference mixes), respectively. Other mixes with Liapor (LP) and Ecoglas (EG) have been prepared with the same volume of aggregate $68.3 \%$ and $57.7 \%$ for each density class. Similarly to the LV specimens, for mixes LP1 and EG1, w/b ratio was constant at 0.43 , while the ratio was set to be 0.77 for the LP2 and EG2 specimens.

The water absorption of lightweight aggregate needs to be carefully controlled in the mixing process, because it is an important parameter which significantly influences the properties of both fresh and hardened concrete. Due 


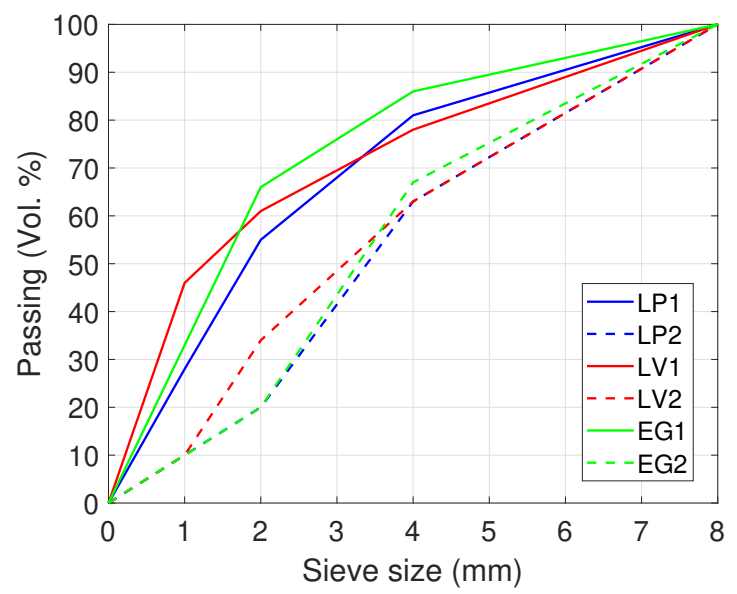

Figure 3: The gradings of the used aggregates for the specimens

Table 3: Composition of LWAC mixture $\left[\mathrm{kg} / \mathrm{m}^{3}\right]$

\begin{tabular}{|c|c|c|c|c|c|c|}
\hline Material & LP1 & LP2 & LV1 & LV2 & EG1 & EG2 \\
\hline Cement & 216 & 405 & 216 & 405 & 216 & 405 \\
\hline MS ${ }^{*}$ & 24 & 45 & 24 & 45 & 24 & 45 \\
\hline Water & 184 & 194 & 184 & 194 & 184 & 194 \\
\hline $\mathbf{S} \mathbf{P}^{* *}$ & 3.8 & 4.5 & 3.8 & 4.5 & 3.8 & 4.5 \\
\hline $\mathbf{S T}^{* * *}$ & 0.9 & 0.7 & 0.9 & 0.7 & 0.9 & 0.7 \\
\hline Liapor $^{\circledR} 2-8 \mathrm{~mm}$ & 95.2 & 128.4 & - & - & - & - \\
\hline Liapor $^{\circledR}$ 2-6 mm & 58.1 & 78.4 & - & - & - & - \\
\hline Liapor ${ }^{\circledR}$ 1-4 mm & 72.7 & 93.1 & - & - & - & - \\
\hline Liapor $^{\circledR}$ 0-2 mm & 268.0 & 45.5 & - & - & - & - \\
\hline Liaver $^{\circledR} 4-8 \mathrm{~mm}$ & - & - & 42.6 & 57.5 & - & - \\
\hline Liaver $^{\circledR} 2-4 \mathrm{~mm}$ & - & - & 33.4 & 45.0 & - & - \\
\hline Liaver ${ }^{\circledR}$ 1-2 mm & - & - & 28.5 & 38.3 & - & - \\
\hline Liaver $^{\circledR}$ 0.5-1 mm & - & - & 89.0 & 15.0 & - & - \\
\hline Ecoglas ${ }^{\circledR} 5-8 \mathrm{~mm}$ & - & - & - & - & 44 & 59.4 \\
\hline Ecoglas ${ }^{\circledR} 2-5 \mathrm{~mm}$ & - & - & - & - & 62.4 & 84.1 \\
\hline Ecoglas ${ }^{\circledR}$ 0-2 mm & - & - & - & - & 207.9 & 35.3 \\
\hline
\end{tabular}

*MS: microsilica, **SP: superplasticizer, ***ST: stabilizer

to differences in water absorption and suction rates of different types of lightweight aggregates, trial mixes were performed to select the appropriate method of mixing. Three different methods were examined: mixing method 1) presoaking of aggregate and adding it to the mixer in saturated surface dry form (SSD); mixing method 2) adding aggregate to the mixer in dry form and then adding extra amount of water equal to the absorption of aggregate to the mixer with the mixing water (w/b); mixing method 3) adding aggregate in dry form without considering extra water. The preliminary results of the trial mixes showed that the mixing method 2 was appropriate for expanded glass (LV mixes) and foamed glass (EG mixes). However, method 1 (presoaking of aggregate for 1 hour) was more proper for 
Table 4: Mechanical and thermal properties of LWAC specimens [53]

\begin{tabular}{ccccccc}
\hline Specimen & LP1 & LP2 & LV1 & LV2 & EG1 & EG2 \\
\hline $\begin{array}{c}\text { Compressive strength } \\
\text { [MPa] }\end{array}$ & 8.57 & 18.3 & 7.2 & 15.3 & 7.88 & 10.56 \\
\hline $\begin{array}{c}\text { Thermal conductivity } \\
{[\mathbf{W} / \mathbf{m} / \mathbf{K}]}\end{array}$ & 0.216 & 0.298 & 0.127 & 0.196 & 0.208 & 0.28 \\
\hline
\end{tabular}

expanded clay aggregate (LP mixes). To mix the concrete ingredients, a Zyklos concrete mixer with a capacity of 50 liters was used. After the addition of the aggregates, the cement, and microsilica, the dry mixture was mixed for 1 min. Thereafter, water, superplasticizer, and stabilizer were added and mixed for an additional 3 min. After mixing, concrete consistency was determined by measuring the flow diameter, as specified in EN 206-1. The cast concrete samples were stored in a curing chamber with a controlled temperature and humidity of $21{ }^{\circ} \mathrm{C}$ and $99 \%$, respectively, until the testing day. Table 4 shows the compressive strength and thermal conductivity of the specimens, which were measured in the previous study [53].

\section{Property evaluation and pore characteristics using different approaches}

\subsection{Oven-dry density and water absorption measurements}

Several tests were conducted to examine the influence of lightweight aggregate type on the pore characteristics and transport properties of hardened lightweight aggregate concrete. Oven-dry densities were measured on cubic samples according to EN 12390-7, and open water porosity was determined using the water displacement method following Archimedes principle of buoyancy [56]. Dry concrete sample was submerged under water to measure the volume of open pores. For these tests, $100 \times 100 \times 100 \mathrm{~mm}^{3}$ cubical steel molds were filled with fresh concrete from each mix, and demolded after $24 \mathrm{~h}$, and cured until the age of $28 \mathrm{~d}$ from casting. One day before testing, the concrete specimens were saturated with water for $24 \mathrm{~h}$ and the saturated mass $\left(m_{\text {sat }}\right)$ was measured. To determine the exact volume of the specimen, the mass under water $\left(m_{s u b}\right)$ was determined. The volume of the sample $(V)$ was measured using Eq. (1). The LWAC specimens were then dried at $105 \pm 5{ }^{\circ} \mathrm{C}$ until constant mass $\left(m_{d r y}\right)$. The oven-dry density $(D)$ can be measured using the following in Eq. (2).

$$
\begin{gathered}
V=\frac{m_{\text {sat }}-m_{\text {sub }}}{\rho_{w}} \\
D=\frac{m_{d r y}}{V}
\end{gathered}
$$

where $\rho_{w}$ is the density of water.

The open water porosity $(P)$ can be calculated using the following formula in Eq. (3): 


$$
P=\frac{m_{s a t}-m_{d r y}}{V} \times 100[\%]
$$

For the transport properties of LWAC, water penetration depth as an indicator for concrete permeability (EN 12390-8) and capillary suction as an indicator for sorptivity (EN ISO 15148) were measured. For the water penetration depth, standard cylindrical steel molds of $150(\phi) \times 300 \mathrm{~mm}^{3}$ were filled with fresh concrete. At the testing age, the water penetration of the LWAC specimens were measured by applying a water pressure of 5 bars for 72 hours. The samples were split, and the depth of penetration was measured at the waterfront. For the capillary suction test, standard $40 \times 40 \times 160 \mathrm{~mm}^{3}$ prisms were filled with fresh concrete and cured until the testing age. For testing, the concrete prisms were dried at $105 \pm 5^{\circ} \mathrm{C}$ until constant mass. After cooling in moisture free conditions, the samples were covered with paraffin on all sides so that water could move only in the vertical direction. In this testing method, capillary suction is the main force that absorbs the water inside the sample, with the concrete samples placed in a water container with a sample immersion depth of $5 \mathrm{~mm}$. From the dry mass of the sample, mass increase can be calculated at different time intervals up to $24 \mathrm{~h}$, making it possible to calculate the water absorption coefficient from the measured results.

\subsection{Micro-CT imaging to evaluate pore characteristics}

To investigate the inner structure of the used LWAC specimens, micro-CT, a noninvasive and nondestructive approach, was adopted. Micro-CT makes it possible to obtain a set of cross-sectional (2D) images such that a 3D volume of the specimen can be visualized by stacking the $2 \mathrm{D}$ images, as shown in Fig. 4 . In the $1^{\text {st }}$ and $2^{\text {nd }}$ images, the cross-section and volume are composed of 1000 pixels (or voxels) along the edge with a $29.7 \mu$ m resolution; these grayscale images expressed in an 8-bit system, which is represented by 256 values (0-255). The pixel/voxel values are determined according to the attenuation factor of the used X-ray and component densities [57, 58]; for instance, the regions described in black can be assumed to be pores, while the brighter parts can be considered as solids with different densities.

For a more detailed investigation, image segmentation is needed so that a specific component, such as aggregate, binder, and pores, can be visualized and examined separately. A multi-thresholding segmentation, using the modified Otsu method [59, 60] as well as a modified watershed algorithm [61], was performed to segment the original microCT images. As shown in Fig. 4, these approaches make it possible to effectively segment and visualize the lightweight aggregates and the pore structure of a target specimen. In each case, the pore and solid characteristics can be evaluated from the segmented images; moreover, the permeability-related property, tortuosity, can also be computed. 


\subsection{Evaluation of permeability properties}

The permeable characteristics of the LWAC specimens were described in terms of tortuosity. Tortuosity used to measure the curvature of a path can also be utilized to examine the pore networks of a target sample. Furthermore, tortuosity allows for the calculation of the relative deviation from the linearity of networked void paths [55, 62]. Tortuosity can be computed using the following path-length ratio approach in Eq. (4):

$$
\tau=C_{c} / L_{s}
$$

where $\tau$ is tortuosity, $C_{c}$ is the actual distance between two end points, which represents the length of the pore channel, and $L_{s}$ is the shortest channel length between the end pores.

The A-star algorithm, an approach for finding the route from a starting location to a target location with minimum cost by avoiding obstacles, was used to compute the channel path $\left(C_{c}\right)$ between inlet and outlet parts of the pores [63]. Fig. 5 shows the schematic of the A-star algorithm. This method is a cost scoring approach composed of the following two functions: $G(t)$, the actual cost of the route from the starting to the temporary locations $(t)$, and $H(t)$, the heuristic cost estimation from the temporary location to the end location. The $G(t)$ can be computed by combining the vertical,

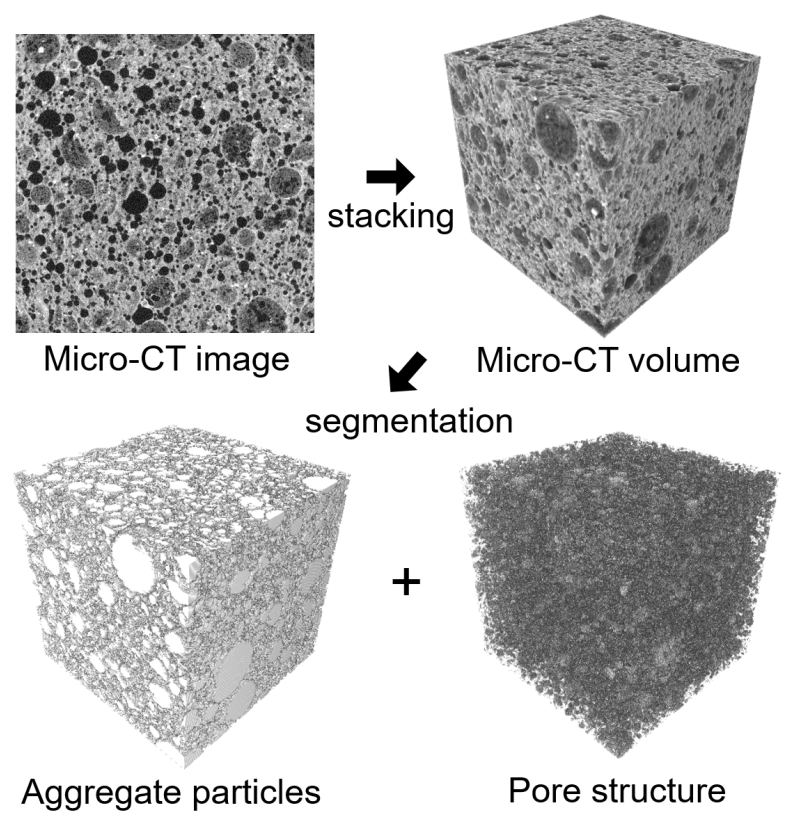

Figure 4: Micro-CT imaging including component segmentation for the LP1 specimen (Note: all voxels in 2D and 3D micro-CT images are expressed in grayscale. In the aggregate image, the white represents lightweight aggregate particles, while in the pore structure image, the dark gray represents pores within the specimen.) 


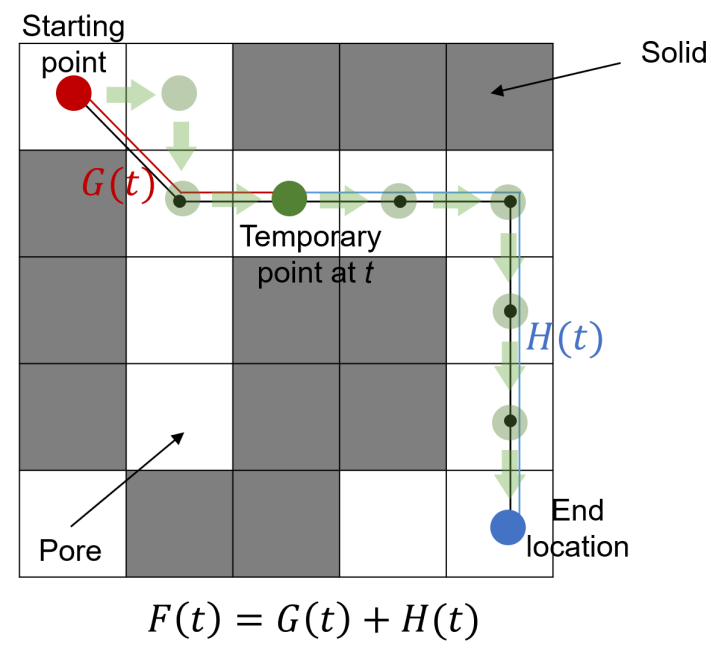

Figure 5: Schematic of the A-star algorithm (Note: the temporary location (t) with green moves from the starting to end points.)

horizontal, and diagonal distances between the starting and the temporary points. The heuristic cost $(H(t))$ can be calculated as the sum of the vertical and horizontal distances from the temporary location to the end location, which is called as the Manhattan distance. The total cost $(F(t))$ between the starting and end points is then computed as the sum of two cost functions: $F(t)=G(t)+H(t)$. The calculation of the total cost proceeds iteratively, with the lowest cost of $F$ in each iteration determined using the A-star algorithm while the temporary location moves from the starting to the end locations. The target pore structures of the specimens were obtained from the micro-CT images, while the measured tortuosity was used to examine the permeability-related characteristics of the LWAC.

\section{Result and discussions}

In this study, the durability-related characteristics and properties of LWAC with different aggregate types and densities were investigated. Pore characteristics, such as porosity and pore size distribution, were evaluated using the obtained micro-CT data. The water absorption and tortuosity of the specimens were also measured using experimental and numerical approaches, respectively. The pore and physical properties were then correlated and discussed below.

\subsection{Oven-dry density of LWAC}

As mentioned earlier, mixes LV1 and LV2 with expanded glass were considered to be the reference mixes. These two mixes were designed to have a theoretical dry density of 600 and $800 \mathrm{~kg} / \mathrm{m}^{3}$, respectively. The measured oven-dry densities of the different mixes were presented in Fig. 6. The results in Fig. 6 show that the actual dry densities of these two reference mixes are 570 and $816 \mathrm{~kg} / \mathrm{m}^{3}$, which falls within the acceptable range for lightweight concrete. 


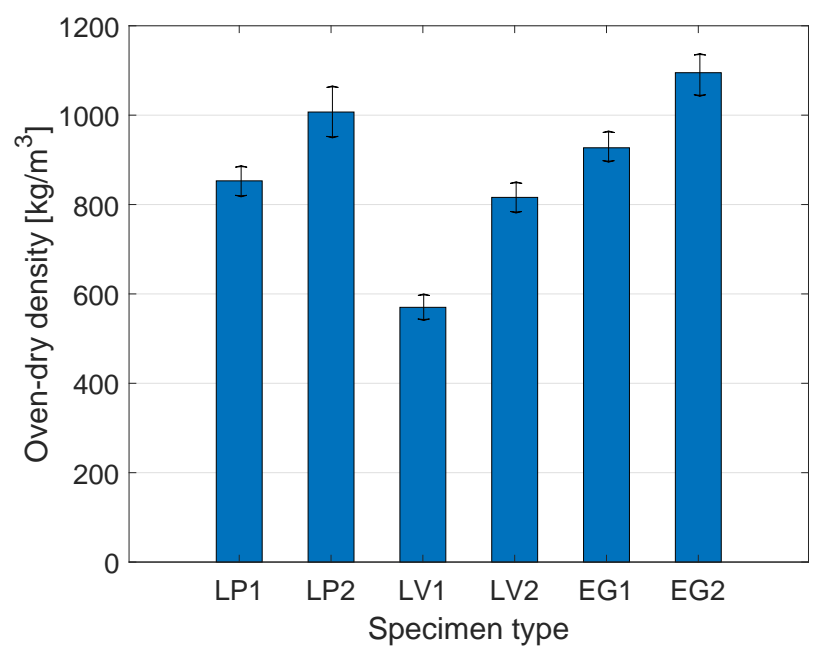

Figure 6: Measured oven-dry density of LWAC with different aggregates

Several researchers reported that the tolerance of lightweight aggregate concrete, in terms of dry density, can be up to $\pm 50 \mathrm{~kg} / \mathrm{m}^{3}[64,65]$, thus confirming that the reference specimens satisfied the requirements of their intended purpose. Upon replacing expanded glass aggregates with other types of aggregate at the same volume, the dry density increased significantly due to the different aggregate particle densities. The aggregate properties mainly determine lightweight concrete density when the binder volume and composition are the same. At the same cement matrix volume and composition, it is the aggregate properties which mainly govern lightweight concrete density. In the case of the incorporation of expanded clay aggregates with a particle density in the range of $540-850 \mathrm{~kg} / \mathrm{m}^{3}$, the dry density obviously increases, compared to the expanded glass aggregate specimens. Similarly, the use of foamed glass aggregates increases the dry density of the lightweight concrete mixes to 927 and $1095 \mathrm{~kg} / \mathrm{m}^{3}$ in the EG1 and EG2 specimens, respectively.

\subsection{Pore characteristics from micro-CT images}

The main difference between LWAC and conventional concrete is the pore structure of the materials. LWAC has a higher porosity and a larger pore size than other concrete in general [57], and, it is therefore important to investigate its pore characteristics properly. Among several pore investigation approaches, in this study, the micro-CT imaging was selected as the nondestructive measurement. The volumetric pore structures of the used LWAC were examined using the image obtained, as shown in Fig. 4.

Fig. 7 shows the pore structures of LWAC with different aggregates and densities. In this figure, only pores larger than the pixel resolution $(29.7 \mu \mathrm{m})$ were taken into consideration. The pores within the binder and the lightweight 


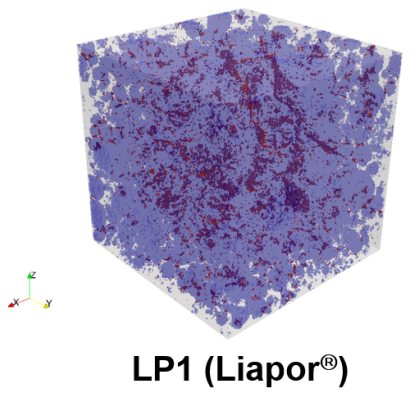

LP1 (Liapor $\left.{ }^{\circledR}\right)$

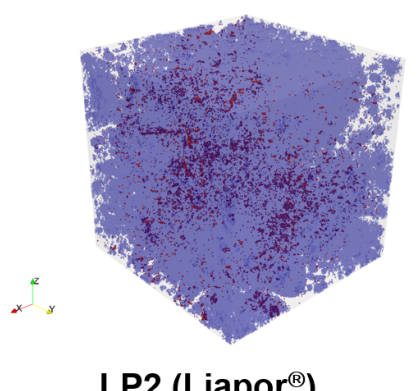

LP2 (Liapor $\left.{ }^{\circledR}\right)$

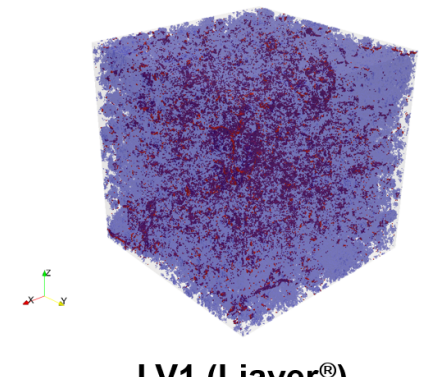

LV1 (Liaver $\left.{ }^{\circledR}\right)$

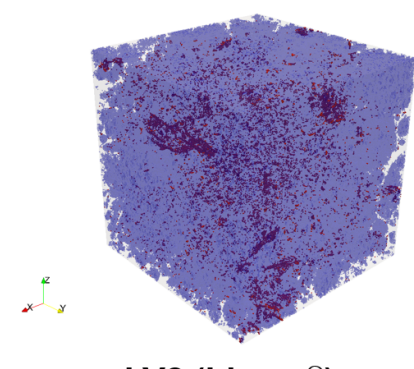

LV2 (Liaver $\left.{ }^{\circledR}\right)$

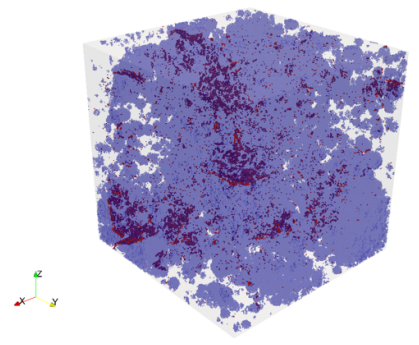

EG1 (Ecoglas $\left.{ }^{\circledR}\right)$

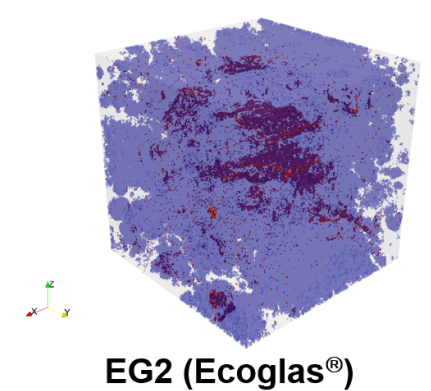

Figure 7: Pore structures of the LWAC with different aggregates and densities (Note: in each specimen, the transparent blue represents the pores in the lightweight aggregates, while the red represents the pores included in the binder region. The transparent gray is the specimen boundary.)

aggregates were classified according to different colors; the former presented in red and the latter in blue. As shown in Fig. 7, the pores included in the lightweight aggregates, depicted in blue, are dominant in the pore structures of the specimens; this is consistent with other studies that demonstrated the effect of lightweight aggregates on the material characteristics $[61,66,67]$. Both the pores of the binder and of the aggregates can be considered as channels through which both ions and fluids can flow. A quantitative porosity investigation is presented in Fig. 8. For each aggregate type, the higher density specimen (designed based on $\mathrm{LV} 800 \mathrm{~kg} / \mathrm{m}^{3}$, series 2) shows lower total porosity than in the case of the series 1 with the lower density specimen. Increasing the volume of lightweight aggregate contributed to reducing material density since lightweight aggregates tend to be more porous than binder materials. The LWAC specimens with lower density contained more lightweight aggregate particles in the same volume, with higher porosity values than in the case of the higher density specimens with more binder content. In Fig. 8, regardless of the aggregate type, the porosity of the binder was almost similar in each density class. The porosity of the lightweight aggregates made up for to more than $70 \%$ of the total porosity in all cases, which can also be discerned visually from the micro-CT images; this confirms that lightweight aggregates are critical in determining the pore characteristics of LWAC. Among the used lightweight aggregates, the material containing the foamed glass shows the highest porosity, indicating that the EG specimen contained the most channels by which fluids could pass. In the expanded granules, 


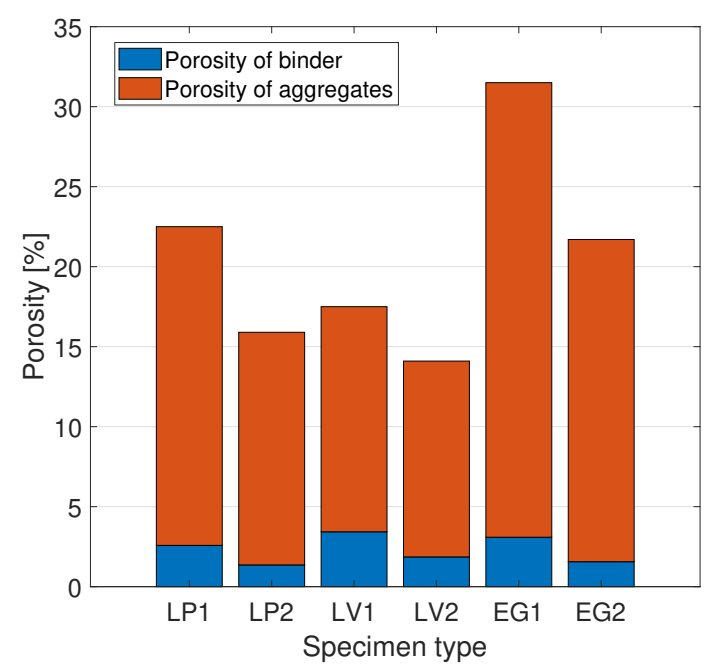

Figure 8: Quantitative porosity information of the LWAC specimens

the expanded clay (LP) was more porous than the expanded glass (LV).

In addition to porosity, Fig. 9 presents the pore size distribution of the LWAC specimens. Despite a similar trend in general, the detailed distributions of the specimens showed a difference according to the aggregate type and density, particularly in the relatively large pores. In all aggregate types, the lower density specimens have a bigger proportion of large pores (> $40 \mu \mathrm{m})$. In the range below $40 \mu \mathrm{m}$, all specimens exhibit similar frequency, with the EG specimens having the largest proportion of the relatively large pores at both density levels. As can be seen in Fig. 7, the pores belonging to the binder tended to be relatively small, while it is assumed that the large pores were from the lightweight aggregates. The pore size distribution results indicate that the foamed glass aggregates had more and coarser pores than the other aggregates, while the expanded glass contained smaller and less pores than in the other cases, which might affect durability-related properties, as is discussed in the following sections.

\subsection{Numerical analysis using micro-CT data}

To investigate the permeable characteristics of the LWAC numerically, the tortuosity of the specimens was computed according to Eq. (4). Tortuosity, as previously mentioned, is a parameter which describes the shortest flow path through a sample. Fig. 10 presents the tortuosity results for the LWAC specimens. In this study, tortuosity denoted in the $x$-axis was determined by the voxel-based calculation. A larger tortuosity value denotes that there is more space in the specimen where fluid can flow, indicating that the material tends to be vulnerable to the external environment. The results indicate that the higher density specimens tended to have a distribution with smaller values than the lower density specimens in each aggregate type. The series 2 specimens with the higher density had lower porosity and 


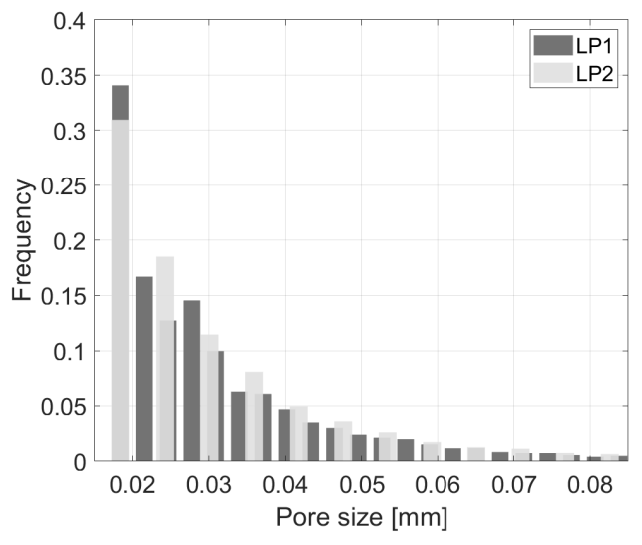

(a)

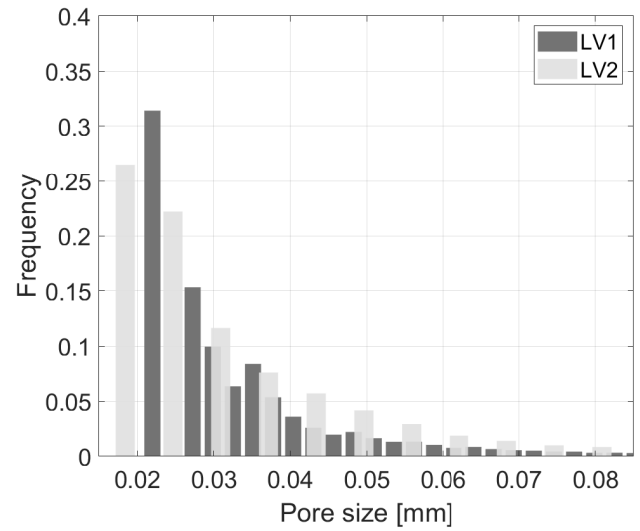

(b)

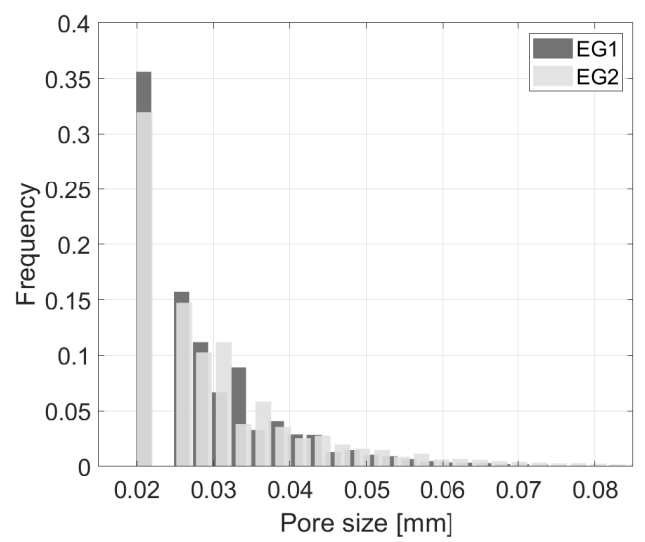

(c)

Figure 9: Comparison of the pore size distribution of the LWAC specimens: (a) LP, (b) LV, (c) EG (Note: pores larger than the pixel size were only considered according to the image resolution.) 

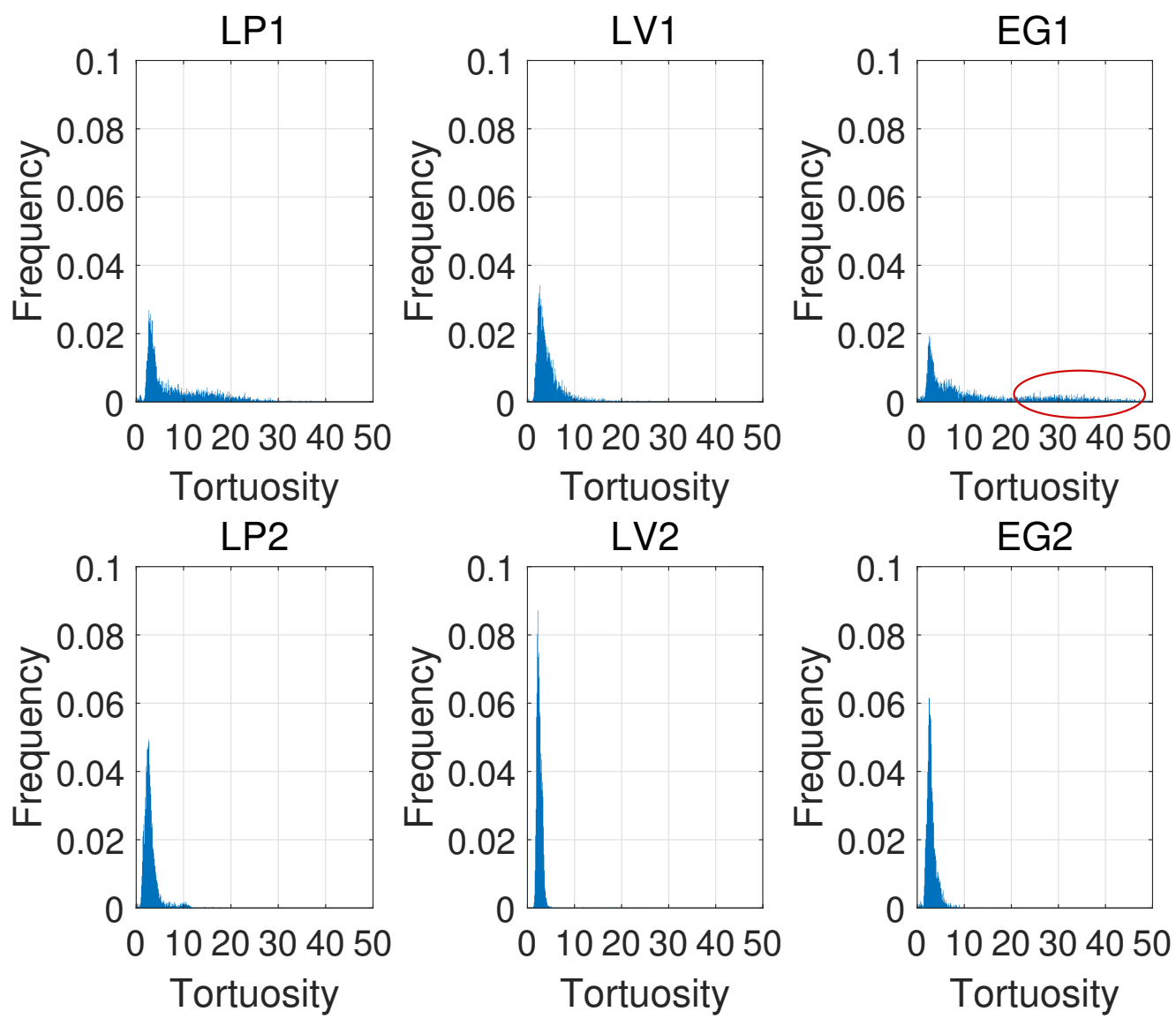

Figure 10: Tortuosity of the LWAC specimens (Note: the $x$-axis denotes the tortousity computed by the voxel-based calculation.)

fewer large pores (> $40 \mu \mathrm{m}$ ) than the lower density specimens, thereby affecting the relatively small tortousity values in general. In particular, most tortuosity values of the higher density specimens are distributed in a range less than 10. On the other hand, the lower density specimens (series 1) show relatively high tortuosity values, particularly in the EG1 specimen, as marked in red in Fig. 10. The EG1 specimen has less short path than in the other cases, while a high tortuosity above 30 was found only in this specimen. As shown in the pore size distribution in Fig. 9, the specimens with foamed glass have relatively more and larger pores, which contributed to the broad and high tortuosity distribution. In the specimens with expanded aggregates, the LP specimens have a higher proportion of tortuosity larger than 10 , compared to any other LV specimen; this is due to the higher porosity and larger pore size that can secure wider and more connected pore channels. The tortuosity results in Fig. 10 indicate that the tortuosity distributions can be varied even in the specimens with the similar porosity range. Thus, tortuosity can be effectively used to examine the permeable characteristics which cannot be described only with porosity. 


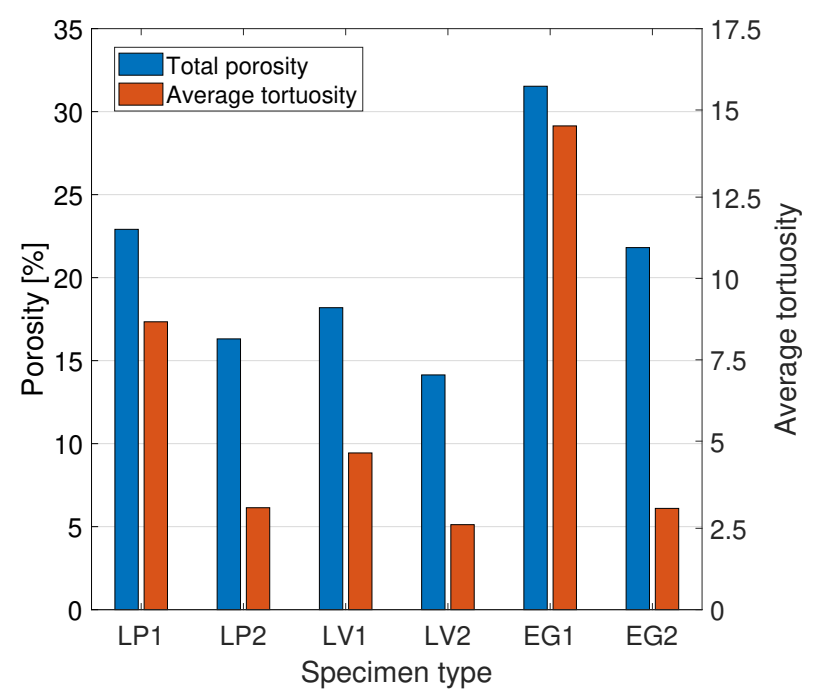

Figure 11: Comparison of total porosity and average tortuosity of the LWAC specimens

The results of a quantitative investigation of the computed tortuosity is presented in Fig. 11. In this figure, the average tortuosity of each specimen is given together with the total porosity. The trend of the average tortuosity tends to coincidence with that of the total porosity, which indicates a close correlation between the pore and permeability characteristics of LWAC. The relative tortuosity is almost the same as the porosity, with the EG1 specimen showing a particularly high average tortuosity. Since foamed glass has more numerous and large pores than other lightweight aggregates, the EG1 specimen, which contained more lightweight aggregate particles than the higher density samples, tended to have more large and continuous pores, which can be confirmed according to porosity and pore size distribution. In contrast, the specimens with expanded glass had the lowest porosity and tortuosity, indicating that these materials were less affected by fluid attacks. Furthermore, the specimens with similar tortuosity, e.g., LP2, LV2, and EG2 specimens, have different porosities, and this indicates that the permeable characteristics of LWAC are strongly affected by aggregate types, not only by porosity. The quantitative results confirm that a proper investigation of durability-related characteristics is needed because LWAC with similar porosity can have different pore structures, such as pore connectivity.

\subsection{Experimental measurements}

In addition to the numerical approaches, several physical and durability-related properties were experimentally measured. The experimental results validated the specimen quality and can be used for correlation with the numerical characteristics. 


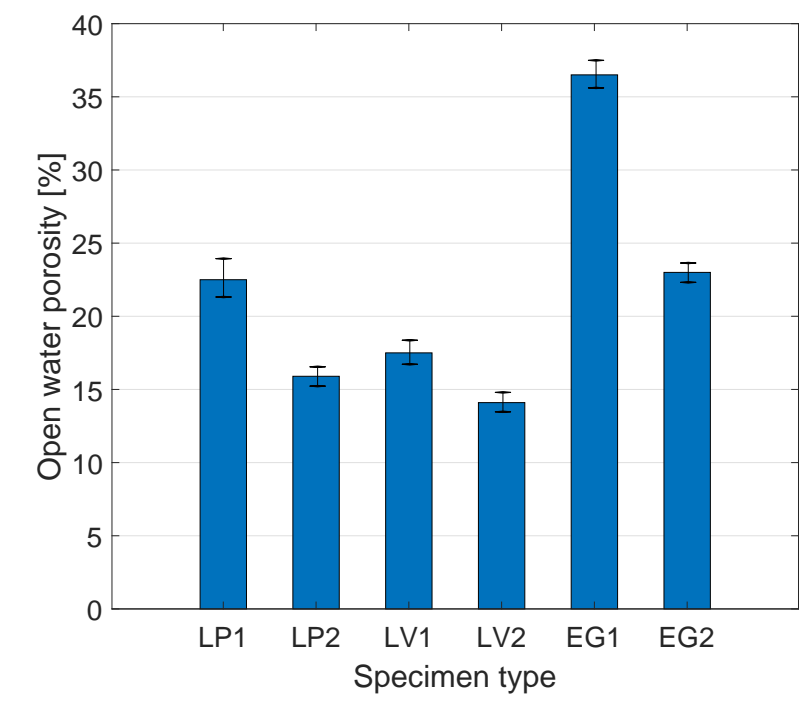

Figure 12: Open water porosity of LWAC with different densities and aggregates

\subsubsection{Open water porosity}

In addition to the micro-CT porosity investigation, the water displacement method (Eq. (3)) was used to determine the volume of open pores which were accessible to water to to confirm the pore characteristics. Fig. 12 presents the measured open water porosity for LWAC specimens with different aggregates. It can be clearly seen that total porosity strongly correlates with concrete density. In all aggregate types, the mixes with the higher density have a lower porosity than mixes with lower density. In the same density class, the types and properties of lightweight aggregates played an important role in determining the open porosity of lightweight aggregate concrete. Ecoglass mixes exhibit the highest open porosity compared to expanded glass and expanded clay at densities of both densities; this can be attributed to the high porosity of foamed glass aggregate compared to other aggregate types. Evidence of this effect can be found in the water absorption of the aggregate particles, as shown in Table 2. The open water porosity test results are in good agreement with the measured water absorption values of the lightweight aggregates. Ecoglass aggregate has a water absorption of about 21-27 wt.-\%, which is much higher than that of expanded clay and expanded glass. The obtained results confirm that the water absorption test can be used as an indicator for predicting the open pore structure inside an aggregate. In Fig. 12, the open water porosity is slightly higher than the values of the measured porosity using micro-CT imaging because very tiny pores, such as capillaries, were also considered in this experiment. Despite the small differences, the overall trend was almost the same with both methods. 


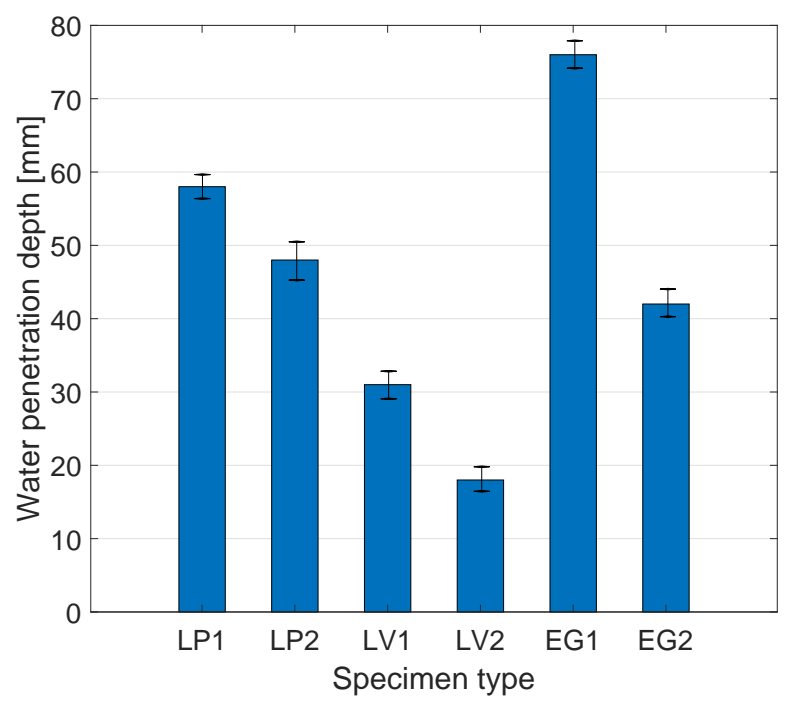

Figure 13: Results of water penetration depth of the LWAC mixes

\subsubsection{Water penetration depth}

Water penetration depth was measured to evaluate concrete permeability in accordance with EN 12390-8. The results were presented in Fig. 13, indicating that concrete permeability strongly depends on its density, or on the volumetric amounts of concrete components. The higher density (series 2) specimens had lower penetration depths than the lower density specimens due to the increased amount of cement matrix and the reduced proportions of lightweight aggregate. However, at the same cementitious materials content and at the same density class, the water penetration depth of porous lightweight aggregates depends on their pore structure and connectivity, which is consistent with the tortuosity results. The higher porosity of foamed glass aggregates, associated with their large pore sizes, facilitates the movement of water under pressure inside the concrete. However, the LWAC specimens containing expanded glass with a high volume of closed pores, which are water inaccessible, and a lower volume of open pores with smaller sizes showed lower penetration depth. The closed pores cannot contribute to the movement of water through the material, with the solids between the pores hindering penetration by water. As a result, the water penetration depth of expanded glass LWAC is much lower than that of expanded clay LWAC at both density levels. The permeability characteristics of LWAC specimens with expanded clay were on the average between that of expanded glass LWAC and foamed glass LWAC. Water penetration depth through concrete depends mainly on pore size and pore connectivity. The results of pore size distribution tests (Fig. 9) show that the EG specimens contained more coarse pores than the expanded glass and expanded clay specimens, which explains the performance of different lightweight concrete mixes in the water penetration test: the coarser the pores the higher the depth of water penetration. 


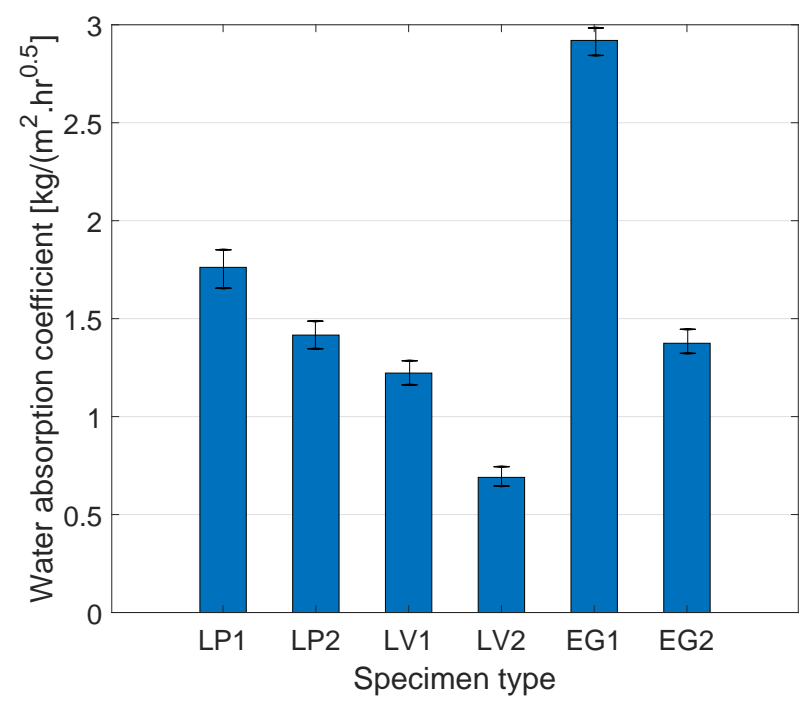

Figure 14: Water absorption coefficient of the LWAC mixes

\subsubsection{Sorptivity}

Concrete sorptivity was determined by measuring the mass increase of concrete samples in accordance with EN ISO 15148. Water sorption inside concrete depends mainly on capillary pore volume, size and connectivity. In sorptivity measurements, only the capillary pores contribute to the movement of water inside concrete since capillary suction is the main force for water motion. The increase in dry concrete mass due to partial submersion in water for up to $24 \mathrm{~h}$ was measured. From the rate of mass increase, the water absorption coefficient (Fig. 14) can be calculated as a measurement of concrete sorptivity. The trend of the sorptivity results was similar to that of the results of open water porosity and water penetration depth. Concrete sorptivity is highly related to the type of aggregate used. At the same density with the same cement matrix, the water absorption coefficient depends on the capillary pore volume and on the connectivity inside the lightweight aggregate. The absorption coefficients were 1.2221 and $0.6897 \mathrm{~kg} /\left(\mathrm{m}^{2} \cdot \mathrm{hr}^{0.5}\right)$ for expanded glass concrete with lower and higher densities, respectively. However, upon replacing the expanded glass with ecoglass aggregate, a sharp increase in the absorption coefficients, to 2.9201 and $1.3744 \mathrm{~kg} /\left(\mathrm{m}^{2} . \mathrm{hr}^{0.5}\right)$, respectively, can be observed. The role of lightweight aggregate porosity on concrete sorptivity is critical, and the selection of aggregate type should be accurate in order to reduce the harmful impacts of water motion inside concrete units.

The obtained results support the notion that the pore structure of LWAC strongly affects permeable characteristics, such as water absorption and tortuosity, and that both porosity and pore size distribution need to be considered in 
examining the relationship between pore structures and durability-related properties. Despite the similar volume of each type of aggregate the transport properties of concrete are not directly correlated with the density of concrete itself, but are mainly attributed to the type of aggregate used. In particular, lightweight aggregates with more porous structures, like foamed glass, are more vulnerable than other kinds, while specimens with expanded glass showed smaller durability-related properties, denoting this the material is less susceptible to fluid attacks.

\section{Conclusions}

This study investigated the effects of lightweight aggregate types on the durability characteristics of lightweight aggregate concrete incorporating a nondestructive measurement. Lightweight aggregates from three different sources were used: expanded glass, expanded clay, and foamed glass. Based on the specimens with expanded glass aggregates with different density levels $\left(600\right.$ and $\left.800 \mathrm{~kg} / \mathrm{m}^{3}\right)$, the aggregate types were only replaced from the mix composition to evaluate a clear effect of aggregate types on the durability-related properties. X-ray micro-CT was utilized for describing the internal structures of the produced lightweight aggregate concrete specimens, and their detailed pore characteristics and permeable characteristics were measured using the obtained micro-CT data. The physical properties of the specimens were also examined using several experimental approaches, with the relationship between the material characteristics and durability-related properties confirmed effectively.

The concluding remarks of this study can be summarized as follows:

- The type of lightweight aggregate strongly affects the physical properties and characteristics of lightweight aggregate concrete. Aggregate particles from different origins can be successfully utilized to produce ultralightweight concrete with a density lower than $1200 \mathrm{~kg} / \mathrm{m}^{3}$.

- X-ray micro-CT can be used to visualize the pore structure of lightweight aggregate concrete. Micro-CT imaging enabled classification of pores in lightweight aggregates and binder, which contributes to understanding the effects of each aggregate on LWAC pore characteristics.

- Tortuosity, a parameter for indicating permeable characteristics, was effectively computed using micro-CT data. The tortuosity results confirmed that the permeable characteristics of lightweight aggregate concrete strongly depend on the type and amount of used aggregates, which can contribute to the dry density of a material. Among the used aggregates, the specimens with foamed glass showed the highest tortuosity, denoting that this material is the most vulnerable, since it contains a wide and long channel path. Conversely, expanded glass is the most effective material in terms of preventing environmental damage caused by fluid. 
- Durability-related properties, such as water penetration depth and the absorption coefficient, showed that the durability of lightweight aggregate concrete is affected by aggregate type, particularly pore structure. Although the material density of expanded clay and foamed glass is higher than that of expanded glass, their porous structures contribute to higher water absorption and penetration depth, which indicates vulnerability to chloride moisture penetration.

- In terms of permeable characteristics, expanded glass is a more beneficial material than expanded clay and foamed glass. Due to their higher porosity, the latter materials can be effectively used for other objectives, such as insulation and noise cancellation. Thus, the appropriate selection of lightweight aggregate needs to be undertaken according to the purpose of use.

In addition to the obtained results in this study, further studies on other lightweight aggregates from different origins can be performed using the systematic tool proposed here. With further investigation and testing, it can be expected to develop advanced ultra-lightweight aggregate materials with better mechanical, durability, and insulation performance.

\section{Acknowledgments}

The project was supported by the Korea Agency for Infrastructure Technology Advancement(KAIA) grant funded by the Ministry of Land, Infrastructure and Transport (Grant 20NANO-B156177-01) and by KOREA HYDRO \& NUCLEAR POWER CO., LTD (No. 2019-TECH-01). The authors would like to thank the German Academy of Exchange Services (DAAD), as well as the Egyptian Science and Technology Development Fund (STDF) through the GE-Seed funding program.

\section{Compliance with ethical standards}

Conflict of interest All Authors declared that they have no conflict of interest.

Ethical approval This article does not contain any studies with human participants or animals performed by any of the authors.

\section{Funding}

This project received funding from the European Unions Horizon 2020 research and innovation program, under the Marie Skłodowska-Curie grant agreement No. 841592. 


\section{References}

[1] P. K. Mehta, P. J. M. Monteiro, Concrete: microstructure, properties and materials, 3rd Ed., McGraw-Hill, New York, 2005.

[2] A. M. Neville, Properties of concrete, Wiley, Chichester, 2012.

[3] G. Samson, A. Phelipot-Mardele, C. Lanos, A review of the thermomechanical properties of lightweight concrete, Magazine of Concrete Research 69 (2020) 201-216.

[4] S.-Y. Chung, M. A. Elrahman, D. Stephan, Effect of different gradings of lightweight aggregates on the properties of concrete, Applied Sciences 7 (2017) 585:1-15.

[5] L. Chica, A. Alzate, Cellular concrete review: new trends for application in construction, Construction and Building Materials 200 (2019) $637-647$.

[6] Z. Huang, T. Zhang, Z. Wen, Proportioning and characterization of portland cement-based ultra-lightweight foam concretes, Construction and Building Materials 79 (2015) 390-396.

[7] M. S. Nadesan, P. Dinakar, Structural concrete using sintered flyash lightweight aggregate: A review, Construction and Building Materials 154 (2017) 928-944.

[8] M. E. Dilli, H. N. Atahan, C. Sengul, A comparison of strength and elastic properties between conventional and lightweight structural concretes designed with expanded clay aggregates, Construction and Building Materials 101 (2015) 260-267.

[9] A. Raj, D. Sathyan, K. M. Mini, Physical and functional characteristics of foam concrete: A review, Construction and Building Materials 221 (2019) 787-799.

[10] S.-Y. Chung, J.-S. Kim, C. Lehmann, D. Stephan, T.-S. Han, M. A. Elrahman, Investigation of phase composition and microstructure of foamed cement paste with different supplementary cementing materials, Cement and Concrete Composites 109 (2020) 103560.

[11] M. R. Ahmed, B. Chen, S. F. A. Shah, Investigate the influence of expanded clay aggregate and silica fume on the properties of lightweight concrete, Construction and Building Materials 220 (2019) 253-266.

[12] C. Arriagada, I. Navarrete, M. Lopez, Understanding the effect of porosity on the mechanical and thermal performance of glass foam lightweight aggregates and the influence of production factors, Construction and Building Materials 228 (2019) 116746.

[13] M. R. Ahmed, B. Chen, Experimental research on the performance of lightweight concrete containing foam and expanded clay aggregate, Composites Part B: Engineering 171 (2019) 46-60.

[14] H.-J. Chen, M.-D. Yang, C.-W. Tang, S.-Y. Wang, Producing synthetic lightweight aggregates from reservoir sediments, Construction and Building Materials 28 (2015) 387-394.

[15] R. Yu, D. V. van Onna, P. Spiesz, Q. L. Yu, H. J. H. Brouwers, Development of ultra-lightweight fibre reinforced concrete applying expanded waste glass, Journal of Cleaner Production 112 (2016) 690-701.

[16] L. H. Nguyen, A.-L. Beaucour, S. Ortola, A. Noumow, Influence of the volume fraction and the nature of fine lightweight aggregates on the thermal and mechanical properties of structural concrete, Construction and Building Materials 51 (2014) $121-132$.

[17] Q. L. Yu, P. Spiesz, H. J. H. Brouwers, Ultra-lightweight concrete: Conceptual design and performance evaluation, Cement and Concrete Composites 61 (2015) 18-28.

[18] M. Aslam, P. Shafigh, M. Alizadej, M. Z. Jumaat, Manufacturing of high-strength lightweight aggregate concrete using blended coarse lightweight aggregates, Journal of Building Engineering 13 (2017) 53-62.

[19] P. Sikora, A. Augustyniak, K. Cendrowski, E. Horszczaruk, T. Rucinska, P. Nawrotek, E. Mijowska, Characterization of mechanical and bactericidal properties of cement mortars containing waste glass aggregate and nanomaterials, Materials 9 (2016) 701.

[20] P. Shafigh, M. A. Nomeli, U. J. Alengaram, H. B. Mahmud, M. Z. Jumaat, Engineering properties of lightweight aggregate concrete containing limestone powder and high volume fly ash, Journal of Cleaner Production 135 (2016) 148-157. 
[21] EN 13055:2016, Lightweight aggregates (May 2016).

[22] G. Samson, C. Lanos, L. Mardele, A review of thermomechanical properties of lightweight concrete, Magazine of Concrete Research 69 (2017) 201-216.

[23] A. Mueller, A. Schnell, K. Ruebner, The manufacture of lightweight aggregates from recycled masonry rubble, Construction and Building Materials 98 (2015) 376-387.

[24] C. Yang, C. Cui, J. Qin, Recycling of low-silicon iron tailings in the production of lightweight aggregates, Ceramics International 41 (2015) $1213-1221$

[25] F. Colangelo, F. Messina, R. Cioffi, Recycling of MSWI fly ash by means of cementitious double step cold bonding pelletization: Technological assessment for the production of lightweight artificial aggregates, Journal of Hazardous Materials 299 (2015) $181-191$.

[26] A. Sales, F. R. Souza, W. N. Santos, A. M. Zimer, F. C. R. Almeida, Lightweight composite concrete produced with water treatment sludge and sawdust: Thermal properties and potential application, Construction and Building Materials 24 (2010) $2446-2453$.

[27] A. Schackow, C. Effting, M. V. Folgueras, S. Guths, G. A. Mendes, Mechanical and thermal properties of lightweight concretes with vermiculite and EPS using air-entraining agent, Construction and Building Materials 57 (2014) 190-197.

[28] M. Chabannes, J.-C. Benezet, L. Clerc, E. Garcia-Diaz, Use of raw rice husk as natural aggregate in a lightweight insulating concrete: An innovative application, Construction and Building Materials 70 (2014) 428-438.

[29] M. Serifou, Z. M. Sbartai, S. Yotte, M. O. Boffoue, E. Emeruwa, F. Bos, A study of concrete made with fine and coarse aggregates recycled from fresh concrete waste, Journal of Construction Engineering 317812 (2013) 1-5.

[30] A. M. Rashad, A synopsis about perlite as building material a best practice guide for civil engineer, Construction and Building Materials 121 (2016) 338-353.

[31] A. M. Rashad, Vermiculite as a construction material a short guide for civil engineer, Construction and Building Materials 125 (2016) 53-62.

[32] A. M. Rashad, Lightweight expanded clay aggregate as a building material an overview, Construction and Building Materials 170 (2018) 757-775.

[33] K. Schumacher, N. Sassmannshausen, C. Pritzel, R. Trettin, Lightweight aggregate concrete with an open structure and a porous matrix with an improved ratio of compressive strength to dry density, Construction and Building Materials 264 (2020) 120167.

[34] T. Z. H. Ting, M. E. Rahman, H. H. Lau, M. Z. Y. Ting, Recent development and perspective of lightweight aggregate based self-compacting concrete, Construction and Building Materials 201 (2019) 763-777.

[35] Q. Jin, V. C. Li, Development of lightweight engineered cementitious composite for durability enhancement of tall concrete wind towers, Cement and Concrete Composites 96 (2019) 87-94.

[36] M. A. Elrahman, M. E. Madawy, S.-Y. Chung, P. Sikora, D. Stephan, Preparation and characterization of ultra-lightweight foamed concrete incorporating lightweight aggregates, Applied Sciences 9 (2019) 1447.

[37] F. Roberz, R. C. G. M. Loonen, P. Hoes, J. L. M. Hensen, Ultra-lightweight concrete: Energy and comfort performance evaluation in relation to buildings with low and high thermal mass, Energy and Buildings 138 (2017) 432-442.

[38] S. Mindess, J. F. Young, D. Darwin, Concrete, 2nd Ed., Prentice Hall, New York, 2002.

[39] C.-L. Hwang, M.-F. Hung, Durability design and performance of self-consolidating lightweight concrete, Construction and Building Materials 19 (2005) 619-626.

[40] S. P. Zhang, L. Zong, Evaluation of relationship between water absorption and durability of concrete materials, Advances in Materials Science and Engineering 2014 (2014) 650373.

[41] Q. L. Yu, P. Spiesz, H. J. H. Brouwers, Development of cement-based lightweight composites Part 1: Mix design methodology and hardened properties, Cement and Concrete Composites 44 (2013) 17-29. 
[42] K. S. Youm, J. Moon, J.-Y. Cho, J. J. Kim, Experimental study on strength and durability of lightweight aggregate concrete containing silica fume, Construction and Building Materials 114 (2016) 517-527.

[43] A. H. Nahhab, A. Ketab, Influence of content and maximum size of light expanded clay aggregate on fresh, strength and durability properties of self-compacting lightweight concrete reinforced with micro steel fibers, Construction and Building Materials 233 (2020) 117922.

[44] K. S. Chia, M.-H. Zhang, Water permeability and chloride penetrability of high-strength lightweight aggregate concrete, Cement and Concrete Research 32 (2002) 639-645.

[45] N. Atmaca, M. L. Abbas, A. Atmaca, Effects of nano-silica on the gas permeability, durability and mechanical properties of high-strength lightweight concrete, Construction and Building Materials 147 (2017) 17-26.

[46] V. Ducman, B. Mirtic, Water vapour permeability of lightweight concrete prepared with different types of lightweight aggregates, Construction and Building Materials 68 (2014) 314-379.

[47] Y. Lo, X. F. Gao, A. P. Jeary, Microstructure of pre-wetted aggregate on lightweight concrete, Building and Environment 34 (1999) $759-764$.

[48] E. Guneyisi, M. Gesoglu, E. Booya, K. Mermerdas, Strength and permeability properties of self-compacting concrete with cold bonded fly ash lightweight aggregate, Construction and Building Materials 74 (2015) 17-24.

[49] J. J. Assaad, A. Mir, Durability of polymer-modified lightweight flowable concrete made using expanded polystyrene, Construction and Building Materials 249 (2020) 118764.

[50] V. M. Sanchez-Fajardo, M. E. Torres, A. J. Moreno, Study of the pore structure of the lightweight concrete block with lapilli as an aggregate to predict the liquid permeability by dielectric spectroscopy, Construction and Building Materials 53 (2014) $225-234$.

[51] R. Lorenzoni, L. Curosu, F. Leonard, S. Paciornik, V. Mechterine, F. A. Silva, G. Bruno, Combined mechanical and 3D microstructural analysis of strain-hardening cement-based composites (SHCC) by in-situ X-ray microtomography, Cement and Concrete Research 136 (2020) 106139.

[52] S.-Y. Chung, T.-S. Han, S.-Y. Kim, T.-H. Lee, Investigation of the permeability of porous concrete reconstructed using probabilistic description methods, Construction and Building Materials 66 (2014) 760-770.

[53] M. A. Elrahman, S.-Y. Chung, D. Stephan, Effect of different expanded aggregates on the properties of lightweight concrete, Magazine of Concrete Research 71 (2019) 95-107.

[54] Z. Wang, D. Zou, T. Liu, A. Zhou, M. Shen, A novel method to predict the mesostructured and performance of previous concrete, Construction and Building Materials 263 (2020) 120117.

[55] N. O. Shanti, V. W. L. Chan, S. R. Stock, F. D. Carlo, K. Thornton, K. T. Faber, X-ray micro-computed tomography and tortuosity calculations of percolating pore networks, Acta Materialia 71 (2014) 126-135.

[56] J. Zhang, G. Ma, R. Ming, X. Cui, L. Li, H. Xu, Numerical study on seepage flow in previous concrete based on 3D CT imaging, Construction and Building Materials 161 (2018) 468-478.

[57] S.-Y. Chung, J.-S. Kim, D. Stephan, T.-S. Han, Overview of the use of micro-computed tomography (micro-CT) to investigate the relation between the material characteristics and properties of cement-based materials, Construction and Building Materials 229 (2019) 116843.

[58] J.-S. Kim, S.-Y. Chung, T.-S. Han, D. Stephan, M. A. Elrahman, Correlation between microstructural characteristics from micro-CT of foamed concrete and mechanical behaviors evaluated by experiments and simulations, Cement and Concrete Composites 112 (2020) 103657.

[59] D.-Y. Huang, C.-H. Wang, Optimal multi-level thresholding using a two-stage otsu optimization approach, Pattern Recognition Letters 30 (2009) 275-284.

[60] Z. Yang, W. Ren, R. Sharma, S. McDonald, M. Mostafavi, Y. Vertyagina, T. J. Marrow, In-situ X-ray computed tomography characterisation of 3d fracture evolution and image-based numerical homogenisation of concrete, Cement and Concrete Composites 75 (2017) 74-83.

[61] S.-Y. Chung, M. A. Elrahman, J.-S. Kim, T.-S. Han, D. Stephan, P. Sikora, Comparison of lightweight aggregate and foamed concrete with 
the same density level using image-based characterizations, Construction and Building Materials 211 (2019) 988-999.

[62] S.-Y. Chung, T.-S. Han, S.-Y. Kim, Reconstruction and evaluation of the air permeability of a cement paste specimen with a void distribution gradient using CT images and numerical methods, Construction and Building Materials 87 (2015) 45-53.

[63] J. M. Montes, F. G. Cuevas, J. Cintas, Electrical and thermal tortuosity in powder compacts, Granular Matter 9 (2007) $401-406$.

[64] Y. Amran, N. Farzadnia, A. Ali, Properties and applications of foamed concrete; a review, Construction and Building Materials 101 (2015) 990-1005.

[65] E. Kuzielova, L. Pach, M. Palou, Effect of activated foaming agent on the foam concrete properties, Construction and Building Materials 125 (2015) 998-1004.

[66] H. J. H. Brouwers, H. J. Radix, Self compacting concrete: theoretical and experimental study, Cement and Concrete Research 35 (2005) 2116-2136.

[67] H. Cui, T. Lo, S. Memon, F. Xing, S. X, Analytical model for compressive strength, elastic modulus and peak strain of structural lightweight aggregate concrete, Construction and Building Materials 36 (2012) 1036-1043. 